\title{
Impact of genetic SLC28 transporter and ITPA variants on ribavirin serum level, hemoglobin drop and therapeutic response in patients with HCV infection
}

\author{
Rau, Monika ; Stickel, Felix ; Russmann, Stefan ; Manser, Christine N ; Becker, Philip P ; Weisskopf, \\ Michael ; Schmitt, Johannes ; Dill, Michael T ; Dufour, Jean-François ; Moradpour, Darius ; Semela, \\ David ; Müllhaupt, Beat ; Geier, Andreas
}

\begin{abstract}
BACKGROUND AIMS: In the last decade pegylated interferon- (Peg-INF- ) plus ribavirin $(\mathrm{RBV})$ was the standard treatment of chronic hepatitis $\mathrm{C}$ for genotype 1 , and it remains the standard for genotypes 2 and 3. Recent studies reported associations between RBV-induced anemia and genetic polymorphisms of concentrative nucleoside transporters such as CNT3 (encoded by SLC28A3) and inosine triphosphatase (encoded by ITPA). We aimed to study genetic determinants of RBV kinetics, efficacy and treatment associated anemia. METHODS: We included 216 patients from two Swiss study cohorts (61\% HCV genotype 1, 39\% genotypes 2 or 3). Patients were analyzed for SLC28A2 single nucleotide polymorphism (SNP) rs11854484, SLC28A3 rs56350726 and SLC28A3 rs10868138 as well as ITPA SNPs rs1127354 and rs7270101 and followed regarding treatment-associated hemoglobin changes and sustained virological response (SVR). In 67 patients RBV serum levels were additionally measured during treatment. RESULTS: Patients with SLC28A2 rs11854484 genotype TT had higher dosage- and body weight-adjusted RBV levels than those with genotypes TC or $\mathrm{CC}(\mathrm{p}=0.02$ and $\mathrm{p}=0.06$ at weeks 4 and 8, respectively). ITPA SNP rs1127354 was associated with hemoglobin drop $3 \mathrm{~g} / \mathrm{dl}$ during treatment in genotype (relative risk $(\mathrm{RR})=2.1,95 \% \mathrm{CI} 1.3-3.5)$ as well as in allelic analyses $(\mathrm{RR}=2.0,95 \% \mathrm{CI}$ 1.2-3.4). SLC28A3 rs56350726 was associated with SVR in genotype ( $R R=2.2 ; 95 \%$ CI 1.1-4.3) as well as in allelic analyses $(\mathrm{RR}=2.0,95 \% \mathrm{CI} 1.1-3.4)$. CONCLUSIONS: The newly identified association between RBV serum levels and SLC28A2 rs11854484 genotype as well as the replicated association of ITPA and SLC28A3 genetic polymorphisms with RBV induced anemia and treatment response may support individualized treatment of chronic hepatitis $\mathrm{C}$ and warrant further investigation in larger studies.
\end{abstract}

DOI: https://doi.org/10.1016/j.jhep.2012.11.027

Posted at the Zurich Open Repository and Archive, University of Zurich

ZORA URL: https://doi.org/10.5167/uzh-69618

Journal Article

Accepted Version

Originally published at:

Rau, Monika; Stickel, Felix; Russmann, Stefan; Manser, Christine N; Becker, Philip P; Weisskopf, Michael; Schmitt, Johannes; Dill, Michael T; Dufour, Jean-François; Moradpour, Darius; Semela, David; Müllhaupt, Beat; Geier, Andreas (2013). Impact of genetic SLC28 transporter and ITPA variants on ribavirin serum level, hemoglobin drop and therapeutic response in patients with HCV infection. Journal of Hepatology, 58(4):669-675. 
DOI: https://doi.org/10.1016/j.jhep.2012.11.027 


\section{Accepted Manuscript}

Impact of genetic SLC28 transporter and ITPA variants on ribavirin serum level, hemoglobin drop and therapeutic response in patients with HCV infection

Monika Rau, Felix Stickel, Stefan Russmann, Christine Manser, Philip Becker, Michael Weisskopf, Johannes Schmitt, Michael T. Dill, Jean-François Dufour, Darius Moradpour, David Semela, Beat Müllhaupt, Andreas Geier

PII: S0168-8278(12)00896-3

DOI: http://dx.doi.org/10.1016/j.jhep.2012.11.027

Reference: JHEPAT 4495

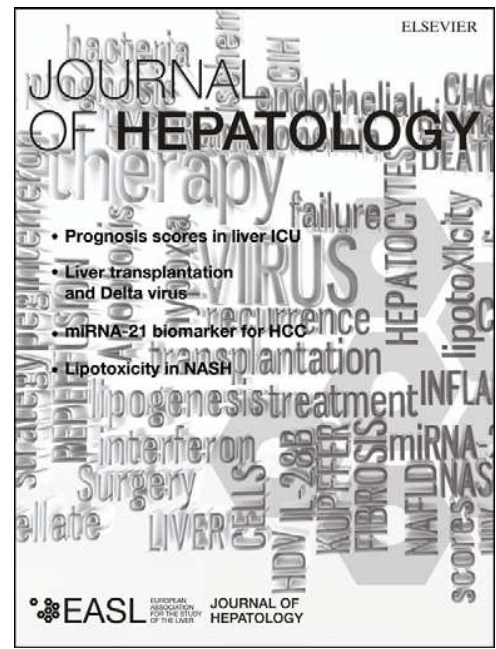

To appear in:

Journal of Hepatology

Received Date:

22 May 2012

Revised Date:

31 October 2012

Accepted Date:

15 November 2012

Please cite this article as: Rau, M., Stickel, F., Russmann, S., Manser, C., Becker, P., Weisskopf, M., Schmitt, J., Dill, M.T., Dufour, J-F., Moradpour, D., Semela, D., Müllhaupt, B., Geier, A., Impact of genetic SLC28 transporter and ITPA variants on ribavirin serum level, hemoglobin drop and therapeutic response in patients with HCV infection, Journal of Hepatology (2012), doi: http://dx.doi.org/10.1016/j.jhep.2012.11.027

This is a PDF file of an unedited manuscript that has been accepted for publication. As a service to our customers we are providing this early version of the manuscript. The manuscript will undergo copyediting, typesetting, and review of the resulting proof before it is published in its final form. Please note that during the production process errors may be discovered which could affect the content, and all legal disclaimers that apply to the journal pertain. 


\section{Impact of genetic SLC28 transporter and ITPA variants on ribavirin serum level, hemoglobin drop and therapeutic response in patients with HCV infection}

Monika Rau ${ }^{1,2}$, Felix Stickel ${ }^{3}$, Stefan Russmann ${ }^{4}$, Christine Manser $^{1}$, Philip Becker $^{1}$, Michael Weisskopf $^{5}$, Johannes Schmitt ${ }^{1},{ }^{2}$, Michael T. Dill ${ }^{6}$, Jean-François Dufour ${ }^{3}$, Darius Moradpour $^{7}$, David Semela ${ }^{8}$, Beat Müllhaupt ${ }^{1}$ and Andreas Geier ${ }^{1,2}$

${ }^{1}$ Department of Gastroenterology and Hepatology, University Hospital Zurich, Zurich, Switzerland

${ }^{2}$ Division of Hepatology, Department of Medicine II, University Hospital Würzburg, Würzburg, Germany

${ }^{3}$ Institute of Clinical Pharmacology and Visceral Research, University of Berne, Berne, Switzerland

${ }^{4}$ Department of Clinical Pharmacology and Toxicology, University Hospital Zurich, Zurich, Switzerland

${ }^{5}$ Clinical Trials Center, University Hospital Zurich, Zurich, Switzerland

${ }^{6}$ Division of Gastroenterology and Hepatology, University Hospital Basel, Basel, Switzerland,

${ }^{7}$ Division of Gastroenterology and Hepatology, Centre Hospitalier Universitaire Vaudois, Lausanne, Switzerland

${ }^{8}$ Kantonsspital St.Gallen, St.Gallen, Switzerland

Word count: 4.900

Corresponding author:

Prof. Dr. Andreas Geier, Lead Division of Hepatology

Medizinische Klinik und Poliklinik II, Universitätsklinikum Würzburg, Deutschland

Phone: ++49 931201402 01, Fax: ++49 931201640201

e-mail: Geier A2@medizin.uni-wuerzburg.de 
Figures : 4

Tables : 4

List of abbreviations :

Direct acting antivirals (DAAs)

Pegylated interferon- $\alpha$ (Peg-INF- $\alpha$ )

Ribavirin (RBV)

Hepatitis C virus (HCV)

Inosine triphosphatase (ITPA)

Single nucleotide polymorphism (SNP)

Early virological response (EVR)

Sustained virological response (SVR)

Hemoglobin $(\mathrm{Hb})$

Genotype (GT)

Inosine triphosphate (ITP)

Concentrative nucleoside transporters (CNTs)

Swiss Hepatitis C Cohort Study (SCCS)

Swiss Association for the Study of the Liver (SASL)

High-performance liquid chromatography mass spectrometry (HPLC/MS)

Peripheral blood mononuclear cells (PBMCs) 


\section{ABSTRACT}

Background \& Aims: In the last decade pegylated interferon- $\alpha$ (Peg-INF- $\alpha$ ) plus ribavirin (RBV) was the standard treatment of chronic hepatitis $C$ for genotype 1 , and it remains the standard for genotypes 2 and 3 . Recent studies reported associations between RBV-induced anemia and genetic polymorphisms of concentrative nucleoside transporters such as CNT3 (encoded by SLC28A3) and inosine triphosphatase (encoded by ITPA). We aimed to study genetic determinants of RBV kinetics, efficacy and treatment associated anemia.

Methods: We included 216 patients from two Swiss study cohorts $(61 \% \mathrm{HCV}$ genotype $1,39 \%$ genotypes 2 or 3 ). Patients were analyzed for SLC28A2 single nucleotide polymorphism (SNP) rs11854484, SLC28A3 rs56350726 and SLC28A3 rs10868138 as well as ITPA SNPs rs1127354 and rs7270101 and followed regarding treatment-associated hemoglobin changes and sustained virological response (SVR). In 67 patients RBV serum levels were additionally measured during treatment.

Results: Patients with SLC28A2 rs11854484 genotype TT had higher dosage- and body weight-adjusted RBV levels than those with genotypes TC or CC $(p=0.02$ and $\mathrm{p}=0.06$ at weeks 4 and 8 , respectively). ITPA SNP rs1127354 was associated with hemoglobin drop $\geq 3 \mathrm{~g} / \mathrm{dl}$ during treatment in genotype (relative risk $(\mathrm{RR})=2.1,95 \% \mathrm{Cl}$ 1.3-3.5) as well as in allelic analyses ( $R R=2.0,95 \% \mathrm{Cl} 1.2-3.4)$. SLC28A3 rs56350726 was associated with SVR in genotype $(R R=2.2 ; 95 \% \mathrm{Cl} 1.1-4.3)$ as well as in allelic analyses $(\mathrm{RR}=2.0,95 \% \mathrm{Cl} 1.1-3.4)$.

Conclusions: The newly identified association between RBV serum levels and SLC28A2 rs11854484 genotype as well as the replicated association of ITPA and SLC28A3 genetic polymorphisms with RBV induced anemia and treatment response 
may support individualized treatment of chronic hepatitis $C$ and warrant further investigation in larger studies.

Key words: Ribavirin, chronic hepatitis C, ITPA, SLC28 transporters, anemia, therapy response 


\section{Introduction}

Worldwide, 130-200 million people are infected with the hepatitis C virus (HCV) and 350,000 people die from HCV related end-stage liver disease each year[1]. For the last decade, standard treatment for chronic hepatitis $\mathrm{C}$ has been combination therapy with pegylated interferon- $\alpha$ (Peg-INF- $\alpha$ ) and ribavirin (RBV)[2]. Although its mechanism of action remains incompletely understood, RBV is important for achieving early virological response (EVR), sustained virological response (SVR) and, in particular, the reduction of relapses[3-5].

In general, RBV is well tolerated, but it frequently induces dose-dependent anemia, requiring dose modifications in up to $22 \%$ of patients[5-6]. Current recommendations call for RBV dose reduction if hemoglobin $(\mathrm{Hb})$ levels drop below $10 \mathrm{~g} / \mathrm{dl}$ and demand treatment discontinuation at a $\mathrm{Hb}$ level $<8.5 \mathrm{~g} / \mathrm{dl}$, or suggest adjuvant treatment with erythropoietic growth factors[7]. However, RBV dose reduction can adversely affect its efficacy[8]. In turn, in a study of 118 untreated HCV genotype (GT) 1 infected patients, a significant $\mathrm{Hb}$ decline during antiviral treatment was associated with a higher SVR rate, while a lack of $\mathrm{Hb}$ decline correlated with decreased SVR[9]. These data suggest that the extent of $\mathrm{Hb}$ decline could be a pharmacodynamic marker of RBV exposure, which may predict its antiviral effect more precisely than the RBV dose.

Several genetic polymorphisms have recently been found to influence RBV induced anemia. A genome-wide association study identified two single nucleotide polymorphisms (SNPs) (rs1127354, rs7270101) in the gene coding for inosine triphosphatase (ITPA), which were associated with RBV related anemia[10]. Interestingly, rs1127354 and rs7270101 were shown to markedly reduce ITPA activity[11], which causes a higher concentration of inosine triphosphate (ITP) in 
erythrocytes[12]. Higher ITP concentrations are believed to protect against RBV induced ATP depletion and consequently anemia[13-14] by substituting for erythrocyte GTP in the biosynthesis of ATP[15]. Interestingly, in the above-mentioned study there was no association between these polymorphisms and treatment response, which would be expected based on such a mechanism.

Another host determinant of interest is the family of concentrative nucleoside transporters (CNTs), encoded by SLC28 genes. CNTs mediate sodium-dependent uptake of nucleosides and their analogues including RBV. CNT2 (encoded by SLC28A2) is a purine-preferring transporter, whereas CNT3 (encoded by SLC28A3) has a more global spectrum for purines and pyrimidines[16]. In the human duodenum, mRNA expression of $S L C 28 A 2$ is 15 -fold higher compared to other uptake transporters[17] and it is also expressed in the kidney as well as other parts of the gut. CNT2 (encoded by SLC28A2) is the main uptake transporter for RBV in the small intestine, mainly the jejunum[18]. In line with its prominent role in RBV uptake, SNP rs11854484 in the coding region was the best independent predictor for SVR in $115 \mathrm{HCV}$-infected patients in the study by D'Avolio et al.[19].

CNT3 (SLC28A3) is considered to be another important target in RBV uptake and metabolism. Transcripts of SLC28A3 are found in the pancreas, the duodenum, the liver and other organs[20]. Recently, genetic polymorphisms rs 10868138G/rs56350726T have been reported as being protective against RBV induced anemia in a population of 169 patients infected with HCV genotype 1, but no association with therapeutic outcomes was found[21].

Replication of genome-wide association studies by a targeted approach in different populations is an important contribution to their validation. In addition, previous studies did not simultaneously evaluate the effects and possible interactions between 
genetic polymorphisms of SLC28 and ITPA. Therefore, the present study aimed to examine the isolated and combined contribution of SLC28 and ITPA variants on RBV plasma concentrations, RBV induced anemia and treatment outcome. 


\section{Materials and Methods}

\section{Study design and patients}

We included 216 patients in the main analyses. Among those 194 patients were from the Swiss Hepatitis C Cohort Study (SCCS)[22] (110 GT 1, 84 GT 2 or GT 3), and another 22 patients from Swiss Association for the Study of the Liver (SASL) study 24 (GT 1). Detailed criteria for selection in both cohorts are presented in Figure 1. In addition, we studied another 13 patients undergoing antiviral therapy with PegINF/RBV plus the more recently introduced direct acting antivirals (DAA) Telaprevir or Boceprevir. However, in order to maintain homogeneity of our study population, these were not included in the main analyses. The study protocol was approved by the responsible ethics committees of all participating centres and informed consent for genetic analyses was obtained from each patient. Baseline patient characteristics are reported in Table 1. All patients received standard treatment with Peg-INF- $\alpha$ and RBV for 24 or 48 weeks according to HCV genotype. Inclusion criteria were age $>18$ years as well as positive anti-HCV antibody test and HCV RNA. Patients with HBV or HIV coinfections (positive HBsAg or anti-HIV antibody), alcohol consumption >40 g/day (assessment by questionnaire) and morbid obesity (BMl $>40 \mathrm{~kg} / \mathrm{m}^{2}$ ) were excluded. As outlined in Figure 1 sustained therapeutic response 6 months after end of treatment was available in 197/216 patients due to loss of follow-up. Hb levels between weeks 4 and 12 were reported in 170/216 patients and used to assess the minimal $\mathrm{Hb}$ level. In a subgroup of 67 patients (45 from the SCCS and 22 from SASL-24) with available genomic DNA, RBV levels were measured at therapy weeks 4 and 8 . RBV levels were adjusted to drug dosage per body weight (mg/kg). Patients received either standard body weight-based dosages (800-1200 mg; $n=36)$ or doses 
adjusted according to target drug levels $>3.7 \mu \mathrm{g} / \mathrm{mL}$ (1400-3200 mg; $\mathrm{n=13}$ ). Since RBV dosage was adjusted during the course of treatment only drug levels at weeks 4 and 8 were used for our analysis. RBV drug levels were determined by highperformance liquid chromatography mass spectrometry (HPLC/MS) (Thermo Finnigan TSQ 7000, Thermo Fisher Scientific, Reinach, Switzerland).

\section{DNA isolation and genotyping}

DNA was isolated from peripheral blood mononuclear cells (PBMCs) by using the QIAmp DNA MiniKit (Qiagen, Valencia, CA). After measurement of DNA concentrations, genotyping for ITPA SNPs rs1127354 (C>A) and rs7270101 (A>C) was performed by using TaqMan SNP genotype assays C_27465000_10/ C_29168507_10 (Applied Biosystems, Carlsbad, CA). For the transporters SLC28A2 and SLC28A3, the following Taqman SNP genotype assays were used: rs11854484 (C>T) C_3079502_10, rs56350726 (A>T) C_25954718_20 and rs10868138 (C>T) C_25954882_20 (Applied Biosystems, Carlsbad, CA). Combined analysis of ITPA function was performed and classified according to the criteria published by Fellay et al.[10], i.e. wildtype (100\% ITPA activity), + (rs7270101 heterozygosity, 60\% IPTA activity), ++ (rs1127354 heterozygosity and rs727101 homozygosity, 30\% ITPA activity) and +++ (combined heterozygosity or rs1127354 homozygosity, very low residual ITPA activity.

\section{Statistical analyses}

Statistical analyses and graphs were done with SPSS (19.0, SPSS Inc., Chicago, IL) and STATA (12.1 for MacOS X, StataCorp, College Station, TX). The observed distribution of homozygous and heterozygous patients was compared to the 
expected distribution according to the NCBI SNP database. Differences in therapeutic response (SVR vs. non-SVR including non-responder, partial responder and relapser) and $\mathrm{Hb}$ drop $>3 \mathrm{~g} / \mathrm{dl}$ were calculated as relative risks with Fisher's exact test-based $95 \%$ confidence intervals. RBV serum levels at weeks 4 and 8 were compared using the non-parametric Wilcoxon-Mann-Whitney-test, where p-values $\leq$ 0.05 were considered as statistically significant. In order to explore potential effects of liver disease stage, we also performed analyses with stratification over the presence of cirrhosis. These allowed us to evaluate relative risk estimates restricted to either non-cirrhotic or cirrhotic patients, as well as combined Mantel-Haenszel pooled estimates with robust control for possible confounding by liver cirrhosis. 


\section{Results}

\section{Allelic and genotype frequencies}

Allelic and genotype frequencies of analyzed genetic variants for ITPA, SLC28A2 and SLC28A3 are listed in Table 2. Allelic and genotype frequencies were comparable to those reported in the NCBI SNP database (www.ncbi.nlm.nih.gov/SNP) except for rs11854484, where the C allele occurred more frequently in our cohort.

\section{RBV concentrations and SLC28 genotypes}

Figure 2 shows RBV concentrations of the three studied SLC28 uptake transporter polymorphisms in the 67 patients with available steady state RBV levels at weeks 4 and 8. Patients carrying the TT genotype of SLC28A2 rs11854484 (Figure 2 A) had higher RBV levels at weeks 4 and 8 than those with TC or CC genotype (mean \pm SD $0.19 \pm 0.06 \mathrm{mg} / \mathrm{l}$ vs. $0.15 \pm 0.06 \mathrm{mg} / \mathrm{l}$ at week $4, \mathrm{p}=0.02$; and $0.21 \pm 0.09 \mathrm{mg} / \mathrm{l}$ vs. $0.17 \pm 0.06 \mathrm{mg} / \mathrm{l}$ at week $8 ; \mathrm{p}=0.06$ ). Part of our study population is from the $\mathrm{SASL}$ study 24, where different RBV dosages were used to obtain certain target RBV levels during treatment. The observation of higher RBV levels in TT genotype (SLC28A2 rs11854484) was also found in the subgroup of SASL-24 patients that were targeted to $\mathrm{RBV}$ drug levels $>3.7 \mu \mathrm{g} / \mathrm{mL}$ and therefore received higher RBV dosages. In contrast, no significant differences were observed for TT vs. CT_CC genotypes of rs56350726 and rs10868138 (Figure 2 B and C). No difference in RBV serum levels was observed in cirrhotic vs. non-cirrhotic patients.

Furthermore 13 patients undergoing antiviral therapy with Peg-INF/RBV and Telaprevir or Boceprevir and available RBV serum levels during therapy weeks 4 and 8 met the inclusion criteria. In this small subcohort we also found higher RBV 
concentrations in patients with TT genotype of SLC28A2 rs11854484 than those with TC or CC genotype $(0.16 \pm 0.08 \mathrm{mg} / \mathrm{l}$ vs. $0.12 \pm 0.08 \mathrm{mg} / \mathrm{l}$ at week 4 ; and $0.26 \pm 0.13$ $\mathrm{mg} / \mathrm{l}$ vs. $0.19 \pm 0.07 \mathrm{mg} / \mathrm{l}$ at week 8 ), but as expected with regard to the small number of patients these differences were statistically not significant.

\section{RBV induced anemia and SLC28A2 and ITPA genotypes}

In 101 of 170 patients (59.4\%) Hb levels dropped $>3 \mathrm{~g} / \mathrm{dl}$ during antiviral treatment. Associations of SLC28 and ITPA polymorphisms with $\mathrm{Hb}$ drop $>3 \mathrm{~g} / \mathrm{dL}$ during antiviral therapy are presented in Table $\mathbf{3}$ and Figure $\mathbf{3 .}$

For SLC28 transporter genetic variants we observed no significant differences. In contrast, homozygous carriers of the ITPA rs1127354 CC genotype had a 2.1 times significantly higher risk for $\mathrm{Hb}$ drop $>3 \mathrm{~g} / \mathrm{dL}$ than patients with CA genotype, and also the allelic analyses indicated a 2 times significantly elevated risk for the $\mathrm{C}$ allele.

In addition Figure 4 presents percentages of patients with pronounced $\mathrm{Hb}$ drop over strata of different ITPA activities based on their genotype (ITPA rs1127354 and rs7270101 combinations according to Fellay's ITPA activity class). As shown, the more pronounced the ITPA deficiency, the lower the risk of RBV induced anemia.

\section{SVR and SLC28 and ITPA genotypes}

Associations of therapeutic outcome with SLC28A and ITPA genetic variants are presented in Table 4 and Figure 3. Carriers of the homozygous SLC28A3 rs56350726 TT genotype had a significantly 2.2 times higher risk for reaching SVR compared to AT and AA carriers. Allelic analysis revealed a similar result with a 2 times higher chance for SVR associated with the $T$ allele. An association with a 
relative risk of 1.5 and 1.4 with borderline statistical significance was detected for SLC28A3 rs10868138 in genotypic and allelic analyses, respectively.

In contrast, no correlation of SVR with ITPA, neither in genotype or allelic analysis nor with its functional Fellay class could be observed.

Furthermore, the combined analysis of overall ITPA activity according to Fellay and SLC28A variants together revealed no significant additive effects on either treatment related anemia or SVR (data not shown).

\section{Genetic associations stratified over the presence of cirrhosis}

Because cirrhotic patients are a difficult to treat population for reaching therapy response in antiviral therapy and the effects of genetic factors may differ in this subpopulation we conducted additional stratified analyses for all associations reported above. However, effect estimates were closely similar when analyses were restricted to patients without cirrhosis (relative risk of homozygous SLC28A3 rs56350726 TT genotype for reaching SVR; RR 2.7, 95\% CI 1.1-6.5), or calculated as pooled estimates from strata with and without cirrhosis according to MantelHaenszel, where also tests for heterogeneity did not indicate statistically significant differences between those two strata. 


\section{Discussion}

Although the precise mechanism of action is still unknown, providing HCV-infected patients with adequate doses of RBV during antiviral treatment is pivotal for achieving an optimal therapeutic response. Thus, the extent of RBV exposure is an important determinant of SVR. However, data on possible associations between RBV levels and polymorphisms of genes determining RBV pharmacokinetics is scarce. Pharmacokinetic studies have recently shown that higher RBV levels during treatment are associated with a higher probability of early, rapid and sustained virological response[23-24]. RBV pharmacokinetics are complex, with high inter- and intrapatient variability[25] and a long terminal elimination half-life. As SLC28A transporters are mainly involved in RBV uptake into cells, they are of particular interest for genetic analysis.

The present study links SLC28A2 rs11854484 polymorphism to higher RBV drug levels during combined Peg-INF-a/RBV treatment, and SLC28A3 rs56350726 variant was associated with SVR in this study. No additive effects of ITPA variants and combined activity could be observed.

To characterize the modulating effect of SLC28 transporter variants on RBV levels during antiviral therapy their associations with RBV drug levels in vivo and treatment related outcome parameters were analyzed. SLC28A2 is the main uptake transporter in the small intestine[18]. Uptake kinetics for different genetic polymorphisms were analyzed in a recent study in Xenopus laevis oocytes[16] but no difference in uptake of RBV in the analyzed genetic variants could be detected in this experimental setting. In contrast to these in vitro uptake kinetics, the presence of homozygote 
alleles TT in our patient population was significantly associated with higher serum RBV levels at both weeks 4 and 8 . Despite these discrepant findings, we conclude from our data that the TT genotype might facilitate RBV absorption in the small intestine, which in turn may lead to increased RBV bioavailability. In support of an increased RBV bioavailability we found also a trend towards increased frequency of treatment related anemia for the same allelic variant in our study population. Finally, a functional consequence of the respective SLC28A2 rs11854484 variant in vivo is also supported by a study from D'Avolio et al. reporting a significant association of SLC28A2 rs11854484 with SVR[19].

Concerning other common genetic uptake transporter variants and their potential impact on RBV induced adverse effects a recent study showed an association between SLC28A3 rs10838138 genotype and SLC28A3 rs56350726/rs10838138 haplotype to RBV induced anemia in $169 \mathrm{HCV}$ patients[21]. Accordingly, the same genetic variants have also been analyzed in the present study population without significant association to a treatment induced $\mathrm{Hb}$ decline of $>3 \mathrm{~g} / \mathrm{dL}$. However, in our study patients with the TT genotype had a significant higher relative chance for reaching SVR than patients with SLC28A3 rs56350726 variant who were protected against anemia[21]. These findings also suggest a functional involvement of SLC28A3 variants, possibly due to an effect on RBV uptake. However, in our subgroup of 49 patients with available RBV levels during treatment we did not observe a significant difference in RBV levels for either rs56350726 or rs10838138. The power of this subgroup analysis is limited and therefore does not preclude such a functional impact of SLC28A3 variants on RBV uptake. 
Recent studies have reproducibly identified polymorphic variation of the ITPA gene leading to enzymatic ITPA deficiency as a major determinant of RBV induced hemolytic anemia[26-29]. ITPA deficiency results from two SNPs rs1127354 (missense variant in exon 2) and rs7270101 (splicing-altering SNP located in the second intron) of which both minor alleles cause reduced or non-detectable ITPA activity. Patients who are heterozygous for rs1127354 and rs7270101 have a lower risk for $\mathrm{Hb}$ drop $>3 \mathrm{~g} / \mathrm{dl}$ during antiviral therapy[10]. This association was confirmed in our study for allelic and genotypic rs 1127354 variants. And similarly to the study by Fellay et al., no association between ITPA polymorphisms and therapy outcome was found. To date ITPA polymorphisms have only been associated to therapy response in selected subgroups of larger study populations[30-31]. Given the demonstrated functional effects on RBV metabolism and uptake at different levels, additive effects together with SLC28A transporter variants on both treatment-induced anemia and therapy success could be hypothesized. However, no such effects of coinheritance were observed in the present study and have not been reported elsewhere to date. In addition, our stratified analyses over the presence of cirrhosis were able to exclude that this factor may have confounded our results.

Most recently, DAAs (Telaprevir and Boceprevir) were registered in the U.S. and Europe for the treatment of patients with HCV GT 1 infection. The decreased viral clearance rates in the RBV free treatment arms of recent clinical studies [32-33] show the importance of RBV as a backbone in combination therapy with DAAs at least in the near future, and treatment-related anemia will remain a clinical challenge. In our patient database we also identified 13 eligible patients with antiviral triple therapy treatment. Due to the small patient number separate analyses of this 
additional population of interest suffered from a lack of statistical power. However results for RBV concentrations and effect estimates for genetic associations did not suggest major differences, and future studies may further investigate this population with current standard of care.

For interpretation of our data, it is important to note that the majority of patients were recruited from the SCCS in a retrospective fashion. Together with the patients from SASL study 24 , the study design allows the recruitment of a considerable number of patients with available RBV levels during treatment simultaneously fulfilling all in- and exclusion criteria (Figure 1). Nevertheless, the power of the RBV level subcohort is still marginal and requires the inclusion of different HCV genotypes.

The present study contributes to the understanding of genetic variants involved in RBV bioavailability as it shows an association of increased RBV levels and hemolytic anemia with SLC28A2 rs11854484 TT genotype. Further associations between SVR and SLC28A3 rs56350726 in this study are well in accordance with increased hemolytic anemia observed in other cohorts. In summary, these data place SLC28A transporter variants in a central position in complex RBV pharmacokinetics. Further understanding of the genetic determinants underlying RBV pharmacokinetics should contribute to optimize an individualized treatment that can be envisaged in the near future. 


\section{References}

[1] Gravitz L. Introduction: a smouldering public-health crisis. Nature 2011;474:S2-4.

[2] Hoofnagle JH, Seeff LB. Peginterferon and ribavirin for chronic hepatitis C. N Engl J Med 2006;355:2444-2451.

[3] Fried MW, Shiffman ML, Reddy KR, Smith C, Marinos G, Goncales FL, Jr., et al. Peginterferon alfa-2a plus ribavirin for chronic hepatitis $C$ virus infection. N Engl $J$ Med 2002;347:975-982.

[4] Kubota R, Komiyama T, Kumagai N, Kimijima M, Mitsuki K, Uetake J, et al. Optimal erythrocyte ribavirin level to reduce the risk of anemia and obtain an early virological response in patients with chronic hepatitis $\mathrm{C}$ caused by genotype $1 \mathrm{~b}$ infection. Hepat Res Treat 2010;2010:495928.

[5] Manns MP, McHutchison JG, Gordon SC, Rustgi VK, Shiffman M, Reindollar R, et al. Peginterferon alfa-2b plus ribavirin compared with interferon alfa-2b plus ribavirin for initial treatment of chronic hepatitis C: a randomised trial. Lancet 2001;358:958-965.

[6] Russmann S, Grattagliano I, Portincasa P, Palmieri VO, Palasciano G. Ribavirininduced anemia: mechanisms, risk factors and related targets for future research. Curr Med Chem 2006;13:3351-3357.

[7] McHutchison JG, Manns MP, Longo DL. Definition and management of anemia in patients infected with hepatitis C virus. Liver Int 2006;26:389-398.

[8] Davis GL, Wong JB, McHutchison JG, Manns MP, Harvey J, Albrecht J. Early virologic response to treatment with peginterferon alfa- $2 \mathrm{~b}$ plus ribavirin in patients with chronic hepatitis C. Hepatology 2003;38:645-652.

[9] Sulkowski MS, Shiffman ML, Afdhal NH, Reddy KR, McCone J, Lee WM, et al. Hepatitis $\mathrm{C}$ virus treatment-related anemia is associated with higher sustained virologic response rate. Gastroenterology 2010;139:1602-1611, 1611 e1601.

[10] Fellay J, Thompson AJ, Ge D, Gumbs CE, Urban TJ, Shianna KV, et al. ITPA gene variants protect against anaemia in patients treated for chronic hepatitis C. Nature;464:405408.

[11] von Ahsen N, Oellerich M, Armstrong VW. Characterization of the inosine triphosphatase (ITPA) gene: haplotype structure, haplotype-phenotype correlation and promoter function. Ther Drug Monit 2008;30:16-22.

[12] Fraser JH, Meyers H, Henderson JF, Brox LW, McCoy EE. Individual variation in inosine triphosphate accumulation in human erythrocytes. Clin Biochem 1975;8:353-364. [13] De Franceschi L, Fattovich G, Turrini F, Ayi K, Brugnara C, Manzato F, et al. Hemolytic anemia induced by ribavirin therapy in patients with chronic hepatitis $\mathrm{C}$ virus infection: role of membrane oxidative damage. Hepatology 2000;31:997-1004.

[14] Grattagliano I, Russmann S, Palmieri VO, Juni P, Bihl F, Portincasa P, et al. Low membrane protein sulfhydrils but not G6PD deficiency predict ribavirin-induced hemolysis in hepatitis C. Hepatology 2004;39:1248-1255.

[15] Hitomi Y, Cirulli ET, Fellay J, McHutchison JG, Thompson AJ, Gumbs CE, et al. Inosine triphosphate protects against ribavirin-induced adenosine triphosphate loss by adenylosuccinate synthase function. Gastroenterology;140:1314-1321.

[16] Owen RP, Gray JH, Taylor TR, Carlson EJ, Huang CC, Kawamoto M, et al. Genetic analysis and functional characterization of polymorphisms in the human concentrative nucleoside transporter, CNT2. Pharmacogenet Genomics 2005;15:83-90.

[17] Shin HC, Landowski CP, Sun D, Vig BS, Kim I, Mittal S, et al. Functional expression and characterization of a sodium-dependent nucleoside transporter hCNT2 cloned from human duodenum. Biochem Biophys Res Commun 2003;307:696-703. 
[18] Patil SD, Ngo LY, Glue P, Unadkat JD. Intestinal absorption of ribavirin is preferentially mediated by the Na+-nucleoside purine (N1) transporter. Pharm Res 1998;15:950-952.

[19] A. D'Avolio AC, M. Siccardi, L. Baietto, M. Simiele, S. Patanella, D. Aguilar Marucco, G. Cariti, A. Calcagno, M. Sciandra, A. Smedile, F.G. De Rosa, S. Bonora, M. Rizzetto, G. Di Perri. SLC28A2 65C>T predict sustained virological response in patients with hepatitis $\mathrm{C}$ treated with interferon and ribavirin, considering all HCV genotype and genotype 1/4. . EASL; 2010; Vienna: Journal of Hepatology; 2010. p. S463.

[20] Ritzel MW, Ng AM, Yao SY, Graham K, Loewen SK, Smith KM, et al. Molecular identification and characterization of novel human and mouse concentrative $\mathrm{Na}+$-nucleoside cotransporter proteins (hCNT3 and mCNT3) broadly selective for purine and pyrimidine nucleosides (system cib). J Biol Chem 2001;276:2914-2927.

[21] Doehring A, Hofmann WP, Schlecker C, Zeuzem S, Sarrazin C, Berg T, et al. Role of nucleoside transporters SLC28A2/3 and SLC29A1/2 genetics in ribavirin therapy: protection against anemia in patients with chronic hepatitis C. Pharmacogenet Genomics;21:289-296.

[22] Prasad L, Spicher VM, Zwahlen M, Rickenbach M, Helbling B, Negro F. Cohort Profile: the Swiss Hepatitis C Cohort Study (SCCS). Int J Epidemiol 2007;36:731-737. [23] Jen JF, Glue P, Gupta S, Zambas D, Hajian G. Population pharmacokinetic and pharmacodynamic analysis of ribavirin in patients with chronic hepatitis C. Ther Drug Monit 2000;22:555-565.

[24] Loustaud-Ratti V, Alain S, Rousseau A, Hubert IF, Sauvage FL, Marquet P, et al. Ribavirin exposure after the first dose is predictive of sustained virological response in chronic hepatitis C. Hepatology 2008;47:1453-1461.

[25] Jain MK, Zoellner C. Role of ribavirin in HCV treatment response: now and in the future. Expert Opin Pharmacother 2010;11:673-683.

[26] Kurosaki M, Tanaka Y, Tanaka K, Suzuki Y, Hoshioka Y, Tamaki N, et al. Relationship between polymorphisms of the inosine triphosphatase gene and anaemia or outcome after treatment with pegylated interferon and ribavirin. Antivir Ther; 16:685-694. [27] Nishimura T, Osaki R, Shioya M, Imaeda H, Aomatsu T, Takeuchi T, et al. Polymorphism of the inosine triphosphate pyrophosphatase gene predicts ribavirin-induced anemia in chronic hepatitis C patients. Mol Med Report;5:517-520.

[28] Sakamoto N, Tanaka Y, Nakagawa M, Yatsuhashi H, Nishiguchi S, Enomoto N, et al. ITPA gene variant protects against anemia induced by pegylated interferon-alpha and ribavirin therapy for Japanese patients with chronic hepatitis C. Hepatol Res;40:1063-1071. [29] Suzuki F, Suzuki Y, Akuta N, Sezaki H, Hirakawa M, Kawamura Y, et al. Influence of ITPA polymorphisms on decreases of hemoglobin during treatment with pegylated interferon, ribavirin, and telaprevir. Hepatology;53:415-421.

[30] Kurosaki M, Tanaka Y, Tanaka K, Suzuki Y, Hoshioka Y, Tamaki N, et al. Relationship between polymorphisms of the inosine triphosphatase gene and anaemia or outcome after treatment with pegylated interferon and ribavirin. Antivir Ther 2011;16:685694.

[31] Thompson A. J. FJ, Ge D., Urban T., Shianna K., Sulkowski M., Muir A., Afdhal N., Jacobson I., Esteban R., Poordad F., Lawitz E., Mc Cone J., Shiffmann M., Galler G., Lee W., Reindollar R., King J., Kwo P., Ghalib R., Freilich B., Nyberg L., Patel K., Tillmann H., Noviello S., Bopari N., Koury K., Pedicone L., Brass C., Albrecht J.K., Goldstein D., Mc Hutchison J.G. Genome wide analysis of patients from the IDEAL study identifies a causal role for ITPA gene variation in ribavirin induced hemolytic anemia. EASL. Vienna: Journal of Hepatology; 2010. p. S470.

[32] S. Zeuzem VS, T. Asselah, JP. Bronowicki, E. Ceausus, A.W. Lohse, A. Streinucercel, L. Preotescu, J. Moussalli, B. Muellhaupt, M. Schuchmann, M. Bourliere, F. Calinas, M. Buti, 
S.K. Roberts, E.J. Gane, J.O. Stern, G. Nehmiz, H. Bonaventura, W.O. Boecher, F.J. Mensa. Virological response too an interferon-free refimen of BI201335 and BI207127, with and withourt ribavirin, in treatment-naive patients with chronic genotype-1 HCV infection: week 12 interim results of the SOUND-C2 study. AASLD. San Francisco: Hepatology; 2011. p. 1436A.

[33] Zeuzem S, Buggisch P, Agarwal K, Marcellin P, Sereni D, Klinker H, et al. The protease inhibitor, GS-9256, and non-nucleoside polymerase inhibitor tegobuvir alone, with ribavirin, or pegylated interferon plus ribavirin in hepatitis C. Hepatology;55:749-758. 


\section{TABLES}

Table 1: Characteristics of the overall study population

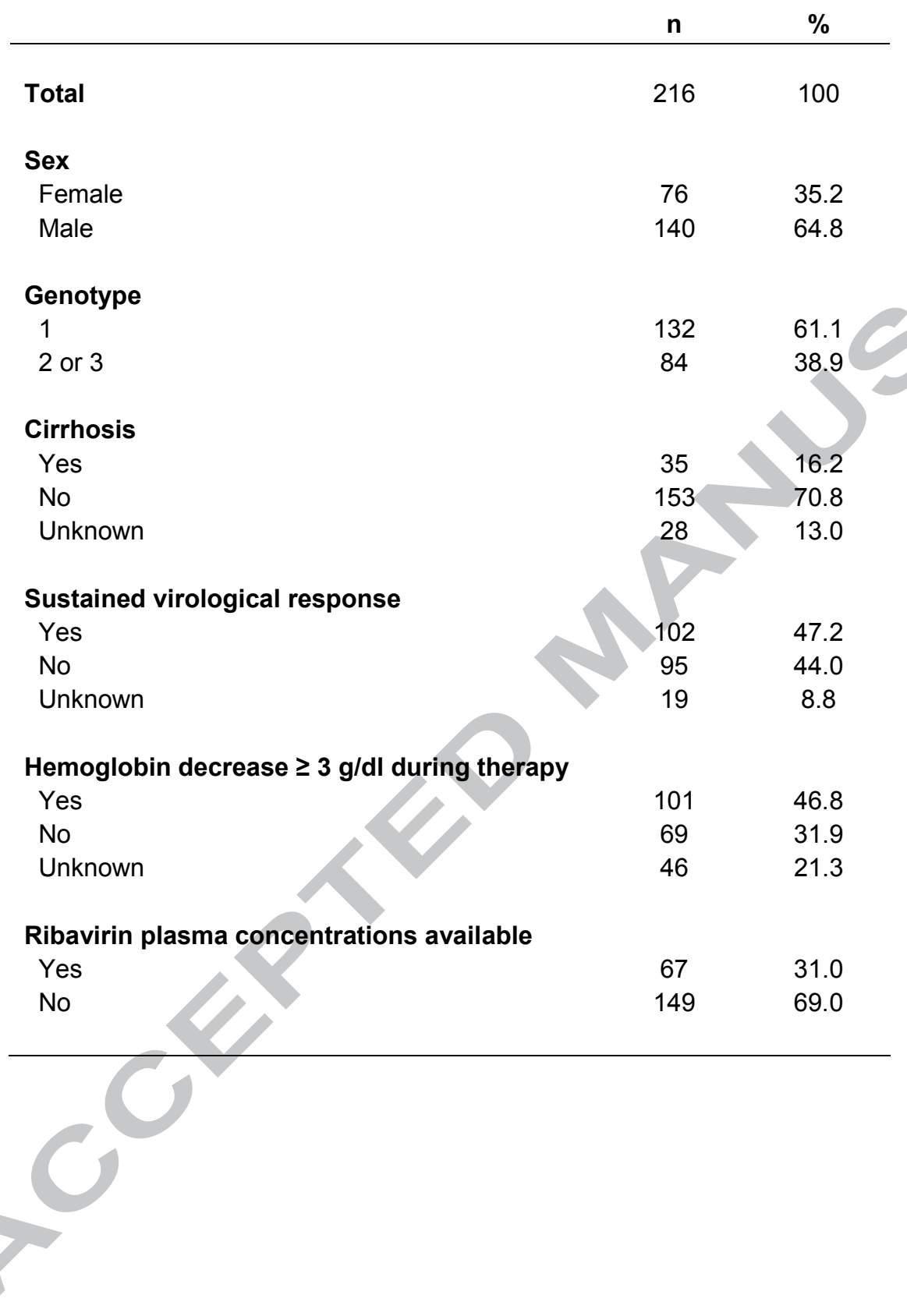


Table 2: Observed and reported allelic frequencies in the study population compared to frequencies reported in the NCBI databank

\begin{tabular}{|c|c|c|}
\hline Allele / SNP & $\begin{array}{c}\text { Proportion }(95 \% \mathrm{Cl}) \text { of alleles in } \\
\text { the study population } \\
(216 \text { patients) }\end{array}$ & $\begin{array}{l}\text { Proportion reported in NCBI } \\
\text { reference population }\end{array}$ \\
\hline \multicolumn{3}{|l|}{ SLC28 genes } \\
\hline \multicolumn{3}{|l|}{ rs11854484 } \\
\hline $\mathrm{T}$ & $0.54(0.49-0.59)$ & 0.64 \\
\hline C & $0.46(0.41-0.51)$ & 0.36 \\
\hline \multicolumn{3}{|l|}{ rs56350726 } \\
\hline $\mathrm{T}$ & $0.94(0.91-0.96)$ & 0.92 \\
\hline$A$ & $0.06(0.04-0.09)$ & 0.08 \\
\hline \multicolumn{3}{|l|}{ rs10868138 } \\
\hline $\mathrm{T}$ & $0.93(0.90-0.95)$ & 0.90 \\
\hline C & $0.07(0.05-0.10)$ & 0.10 \\
\hline \multicolumn{3}{|l|}{ ITPA genes } \\
\hline \multicolumn{3}{|l|}{ rs1127354 } \\
\hline C & $0.94(0.92-0.96)$ & 0.92 \\
\hline A & $0.06(0.04-0.08)$ & 0.08 \\
\hline \multicolumn{3}{|l|}{ rs7270101 } \\
\hline A & $0.86(0.83-0.89)$ & 0.87 \\
\hline C & $0.14(0.11-0.17)$ & 0.13 \\
\hline
\end{tabular}


Table 3: Absolute risks and risk ratios (RR) for $\mathrm{Hb}$ decreases $\geq 3 \mathrm{~g} / \mathrm{dl}$ by genotype in 170 patients with available $\mathrm{Hb}$ measurements

\begin{tabular}{|c|c|c|c|c|c|}
\hline Genotype & Variant 1 & Risk (\%)* & Variant 2 & Risk (\%)* & $\operatorname{RR}(95 \% \mathrm{Cl})^{\star *}$ \\
\hline \multicolumn{6}{|l|}{ SLC28 } \\
\hline rs11854484 & CT or CC & 57.1 & TT & 64.7 & $1.1(0.9-1.5)$ \\
\hline rs56350726 & AT or AA & 55.5 & TT & 59.9 & $1.1(0.7-1.6)$ \\
\hline rs10868138 & $\mathrm{TC}$ or $\mathrm{CC}$ & 56.5 & TT & 59.9 & $1.1(0.7-1.5)$ \\
\hline \multicolumn{6}{|l|}{ ITPA } \\
\hline rs1127354 & $\mathrm{CA}$ & 30.0 & $\mathrm{CC}$ & 63.3 & $2.1(1.3-3.5)$ \\
\hline rs7270101 & $\mathrm{CA}$ or $\mathrm{CC}$ & 48.8 & AA & 63.0 & $1.3(0.9-1.8)$ \\
\hline Allele & Variant 1 & Risk (\%)* & Variant 2 & Risk (\%) & $\operatorname{RR}(95 \% \mathrm{Cl})^{* *}$ \\
\hline \multicolumn{6}{|l|}{ SLC28 } \\
\hline rs11854484 & C & 55.6 & T & 62.4 & $1.1(0.9-1.3)$ \\
\hline rs56350726 & $A$ & 59.1 & $\mathrm{~T}$ & 59.4 & $1.0(0.7-1.4)$ \\
\hline rs10868138 & C & 60.7 & - & 59.3 & $1.0(0.7-1.3)$ \\
\hline \multicolumn{6}{|l|}{ ITPA } \\
\hline rs1127354 & A & 30.0 & C & 61.3 & $2.0(1.2-3.4)$ \\
\hline rs7270101 & C & 49.0 & A & 61.2 & $1.2(1.0-1.6)$ \\
\hline
\end{tabular}

*Absolute risk (\%) of $\mathrm{Hb}$ decrease $\geq 3 \mathrm{~g} / \mathrm{dl}$ for patients with respective gene variants

${ }^{* *}$ Risk ratio with variant 1 as reference (risk variant 2 / risk variant 1 ) 
Table 4: Absolute risks and risk ratios (RR) for SVR by genotype in 197 patients with known therapeutic response

\begin{tabular}{|c|c|c|c|c|c|}
\hline Genotype & Variant 1 & Risk (\%) & Variant 2 & Risk (\%) & $\operatorname{RR}(95 \% \mathrm{Cl})^{\star *}$ \\
\hline \multicolumn{6}{|l|}{ SLC28 } \\
\hline rs11854484 & CT or CC & 52.5 & TT & 50.0 & $1.0(0.7-1.3)$ \\
\hline rs56350726 & AT or AA & 25.0 & TT & 54.1 & $2.2(1.1-4.3)$ \\
\hline rs10868138 & $\mathrm{TC}$ or $\mathrm{CC}$ & 38.1 & TT & 53.4 & $1.4(0.9-2.3)$ \\
\hline \multicolumn{6}{|l|}{ ITPA } \\
\hline rs1127354 & CA & 60.9 & $\mathrm{CC}$ & 50.6 & $0.8(0.6-1.2)$ \\
\hline rs7270101 & CA or CC & 56.3 & AA & 50.3 & $0.9(0.7-1.2)$ \\
\hline Allele & Variant 1 & Risk (\%)* & Variant 2 & Risk (\%)* & $\operatorname{RR}(95 \% \mathrm{Cl})^{\star *}$ \\
\hline \multicolumn{6}{|l|}{ SLC28 } \\
\hline rs11854484 & C & 50.8 & $\mathrm{~T}$ & 52.3 & $1.0(0.9-1.3)$ \\
\hline rs56350726 & A & 27.2 & $T$ & 53.2 & $2.0(1.1-3.4)$ \\
\hline rs10868138 & C & 34.6 & $\mathrm{~T}$ & 53.0 & $1.5(1.0-2.4)$ \\
\hline \multicolumn{6}{|l|}{ ITPA } \\
\hline rs1127354 & A & 60.9 & C & 51.2 & $0.8(0.6-1.2)$ \\
\hline rs7270101 & $\mathrm{C}$ & 52.6 & $A$ & 51.6 & $1.0(0.7-1.3)$ \\
\hline
\end{tabular}

*Absolute risk (\%) of SVR for patients with respective gene variants

${ }^{* *}$ Risk ratio with variant 1 as reference (risk variant 2 / risk variant 1 ) 


\section{FIGURE LEGENDS}

Figure 1: Patient recruitment with inclusion and exclusion criteria.

Figure 2: Boxplots for RBV plasma levels (adjusted to RBV dose/body weight) at weeks 4 and 8 during antiviral treatment by genetic SLC28A2 and SLC28A3 variants in 67 patients.

Figure 3: Frequencies of SLC28 and ITPA genotypes, stratified over categories of Hb drop $(\mathrm{N}=170)$ and SVR $(\mathrm{N}=197)$

Figure 4: Association between ITPA deficiency and proportion of patients with $\mathrm{Hb}$ decreases $\geq 3 \mathrm{~g} / \mathrm{dl}$.

$+++=$ low residual ITPA activity with combined heterozygosity or rs1127354

homozygosity $++=30 \%$ ITPA activity with rs 1127354 heterozygosity or rs 7270101 homozygosity

$+=60 \%$ ITPA activity with rs7270101 heterozygosity

none = wildtype ITPA activity. 


\section{Swiss Hepatitis C Cohort Study (SCCS)}

Adult patients ( $\geq 18$ years) and $\mathrm{HCV}$ antibody positive by immunoblot

Exclusion criteria:

coinfection with HBV or HIV, alcohol

$>40 \mathrm{~g} /$ day and morbid obesity $(\mathrm{BMl}>40)$

\section{Swiss Association for the Study of}

Liver Diseases Study (SASL-24)

Adult patients (18-65 years) and HCV antibody positive by immunoblot, GT 1

Exclusion criteria:

coinfection with HBV or HIV, alcohol $>40 \mathrm{~g} /$ day, prior RBV treatment
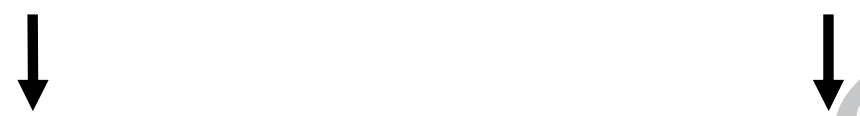

Inclusion criteria: combined therapy with Peg-IFN- $\alpha$ and RBV, available blood samples and genetic consent

$\checkmark$

Total Study Cohort N=216 ( $\mathrm{N}=110 \mathrm{HCV}-1, \mathrm{~N}=84 \mathrm{HCV}-2 / 3)$

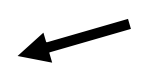

$\checkmark$

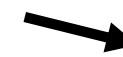

Therapy response $\mathrm{N}=197$

$\mathrm{Hb}$ level $\mathrm{N}=\mathbf{1 7 0}$

RBV level $\mathbf{N}=\mathbf{6 7}$ 
SLC28A2 rs11854484

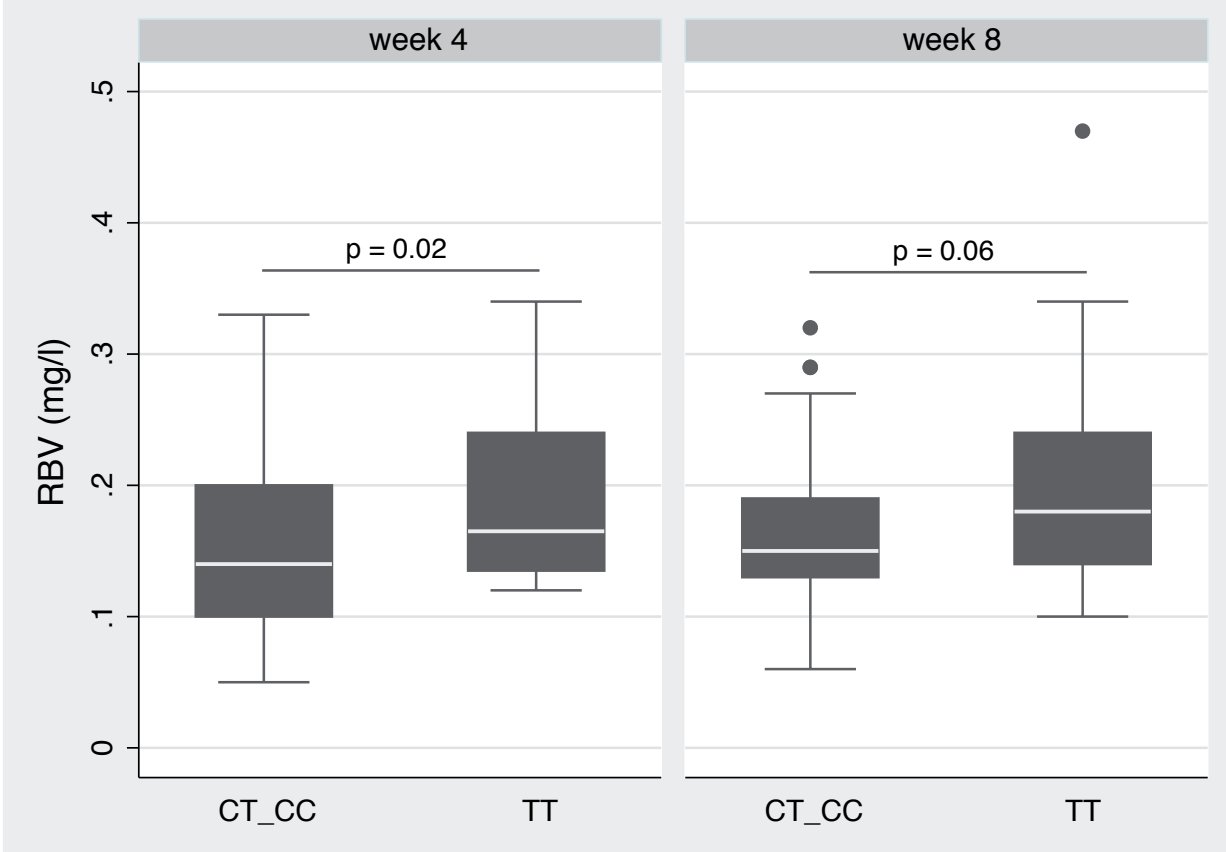

B

SLC28A3 rs56350726

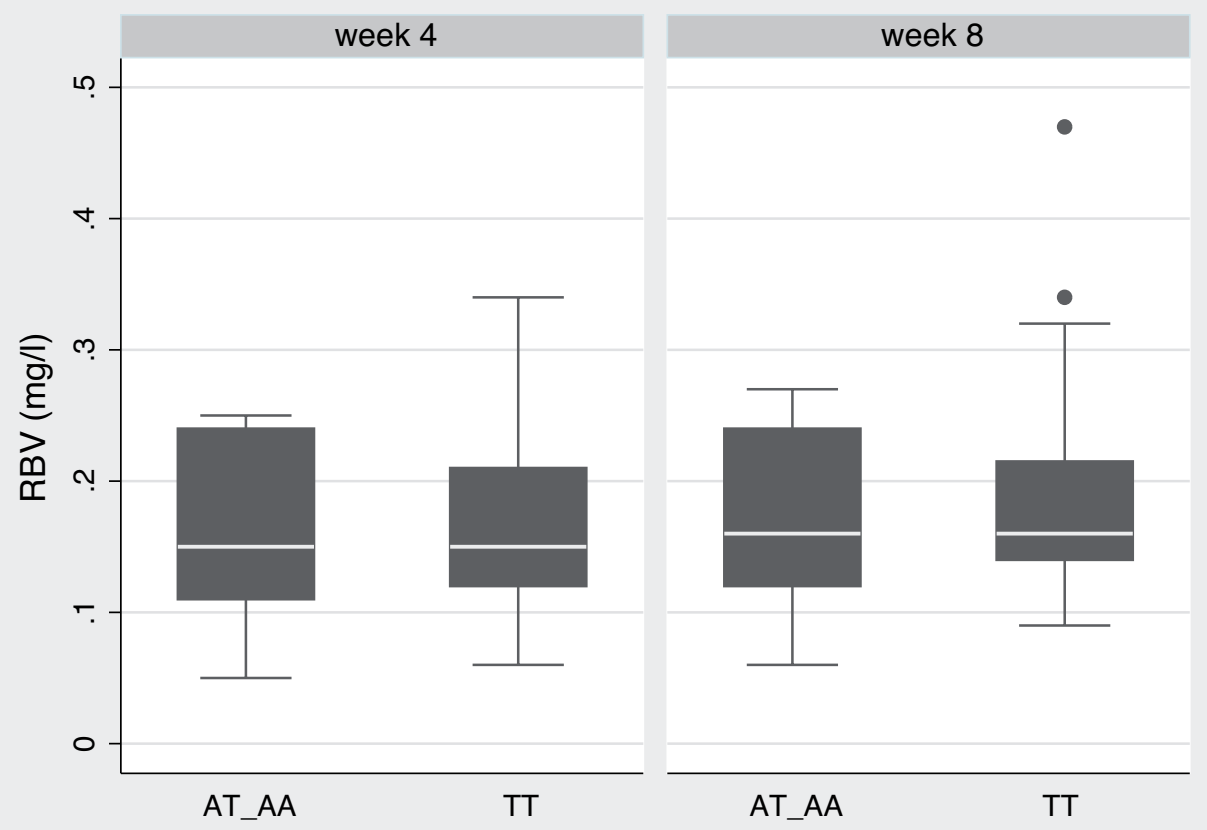

C

SLC28A3 rs10868138

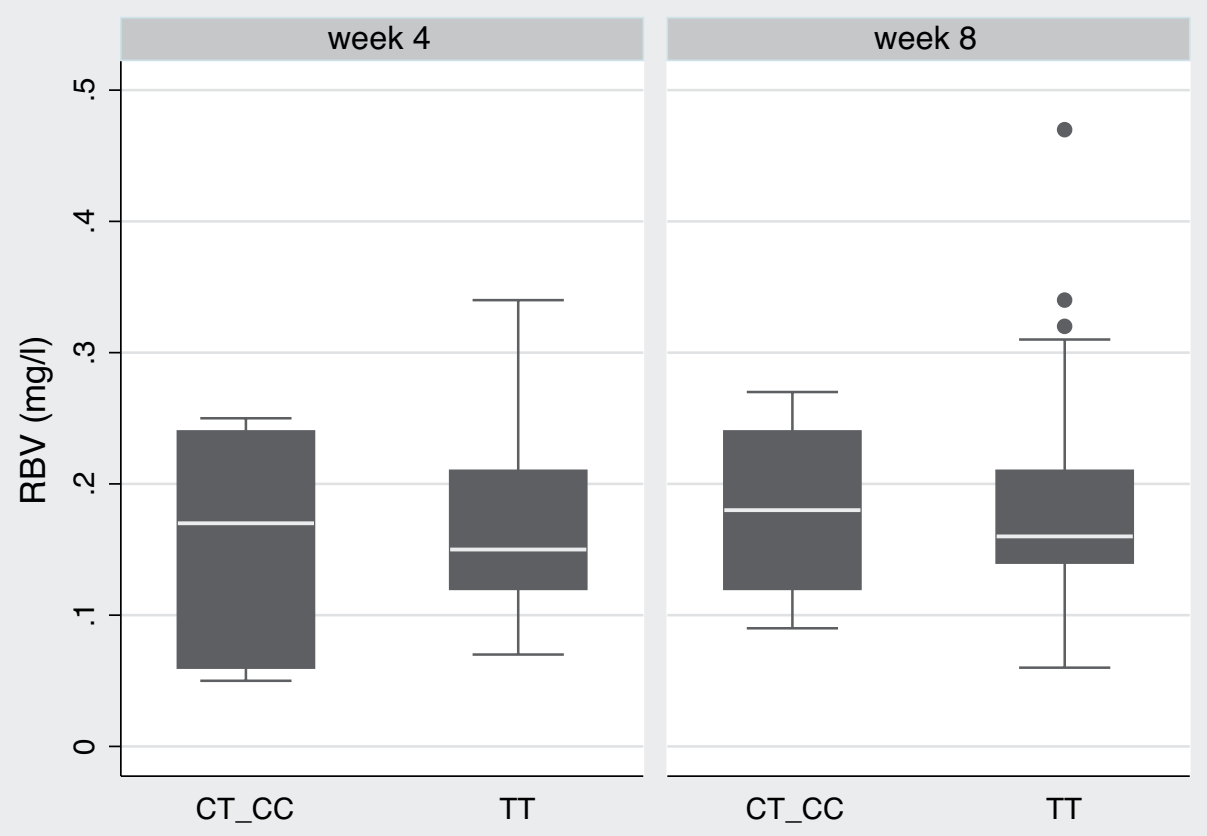




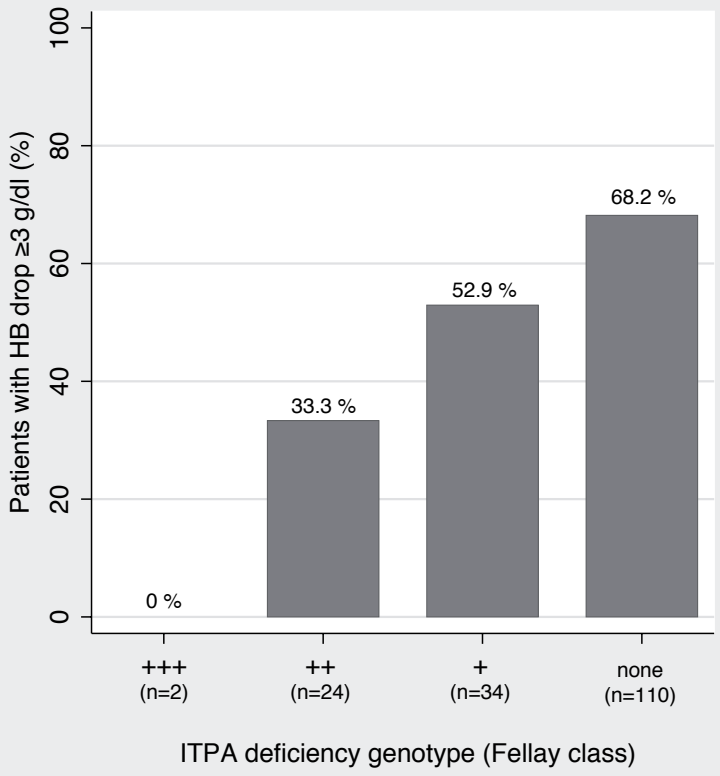

